\title{
Living Protection and Development of Traditional Artistic Handicrafts: A Case Study from "Bamboo Weaving by Family Liu" in Quxian County of Sichuan Province
}

\author{
Peng Lin \\ Fine Arts School of Sichuan University of Arts and Sciences, Dazhou, China \\ Email: P119800710@163.com
}

How to cite this paper: Lin, P. (2018). Living Protection and Development of Traditional Artistic Handicrafts: A Case Study from "Bamboo Weaving by Family Liu" in Quxian County of Sichuan Province. Art and Design Review, 6, 160-167. https://doi.org/10.4236/adr.2018.63016

Received: June 4, 2018

Accepted: August 18, 2018

Published: August 21, 2018

Copyright $\odot 2018$ by author and Scientific Research Publishing Inc. This work is licensed under the Creative Commons Attribution International License (CC BY 4.0).

http://creativecommons.org/licenses/by/4.0/

\begin{abstract}
The heritage and development of the folk handicrafts have hold some chances yet are challenged by the development of China's economy and the progress of the whole plan between the rural and urban. The folk handcrafts are the main contents of the intangible cultural heritages in China and it is important to protect it, to strengthen its inheritance and innovation and to design efficient product chains. The handicraft of "Bamboo Weaving by Family Liu" in Quxian County of Sichuan Province is of some technique and art values, the heritage, protection and development of which have some representativeness and research values.
\end{abstract}

\section{Keywords}

Intangible Cultural Heritages, "Bamboo Weaving by Family Liu" in Quxian County

\section{Introduction}

Among the "Bamboo Weaving" in Sichuan Province, the one from Quxian County is outstanding with its own unique features and local colors. The weaving art is centered around Qujian Town which was honored of "The Homeland of China's Bamboo Weaving Arts", the best one among which is "Bamboo Weaving by Family Liu" ("Liu's Bamboo Weaving"). The "Liu's Bamboo Weaving" is various and highly skilled. With the change of time, it developed new forms: it skillfully combines the plane with the solid and the calligraphies and/or pictures are weaved out, which is named the "Jacquard Bamboo Weaving" and 
was listed in "The Second Batch of National Intangible Cultural Heritages" by the State Council in 2008. By a series of relevant measures to protect, "Liu's Bamboo Weaving" has formed a perfect procedure of living protection, including archive, study, protection, publicity, inheritage and development, thus the bamboo weaving art is in a better protection and the folk handcraft is in a more blooming life. Sinocalamus affinis is its main material and the weaving is made to be tools or daily life utensils. Its art is technically skilful with rich cultures and so it is one of the most Chinese-characteristics folk handcrafts, which is the most representative handcraft in Sichuan or even in China. After a survey of the former studies, the paper discusses about the full heritage and development of "Liu's Bamboo Weaving" in order to make suggestions of the art works' heritage and protection in China (Figure 1).

The globalization and the China's rising results in the attention from the whole world to the intangible cultural inheritage of China and the ones from China rank the first in the 166 outstanding items of the "Human Intangible Cultural Inheritage Roster” promulgated by UNESCO. Though the protection sense of traditional culture from the public is increasing and the attention from government is paid more to, yet the folk handcraft is challenged by the economical development and faster urbanization. As a representative handcraft, "Liu's Bamboo Weaving" should be inherited, protected and developed, and the study is of great significance (Ji, 2016).

The Bamboo Weaving in Quxian County has its own unique features among the ones in Sichuan. After the inheritage, the successive improvement and innovation, it has turned into a school with an Eastern Sichuan Style and is honored of the "Homeland of Bamboo Weaving Art in China" because of its higher artful level. Though it was rising or falling in different times, the bamboo weaving has

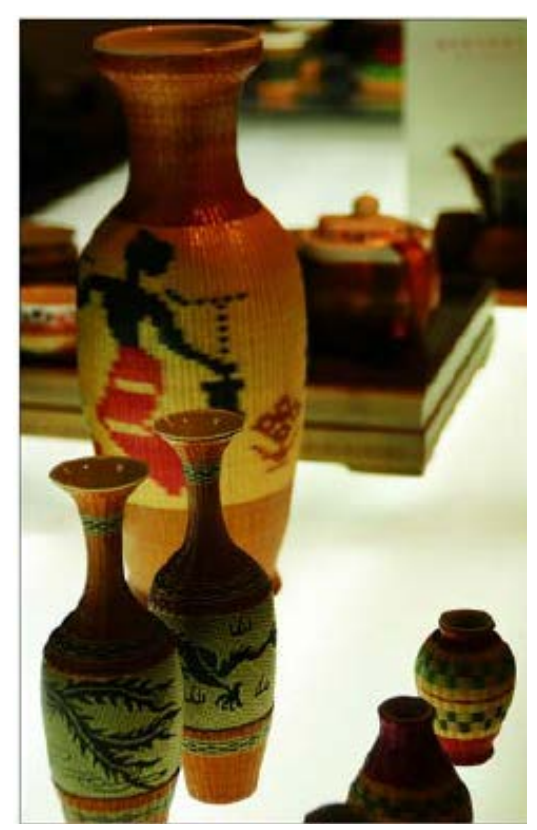

Figure 1. Bamboo Weaving from Quxian County. 
been inherited and developed and at last grown up into an art, an art form which originated from lives and higher than the lives. The faster development of "Liu's Bamboo Weaving" can be traced back to the period of the birth of New China, during which its types and skills were enriched and improved. In 1970s, Liu Jiafeng, as a successor to the weaving, applied the principles of the jacquard into the weaving and created a new form of unique bamboo weaving. The "Jacquard Weaving" (Figure 2) stresses on the design of pictures, such as hills or rivers, flowers or birds, and figures, and then in 1980 the calligraphies or paintings were first time adopted and a series of new types were created including the two-sides of bamboo weaving (Figure 3). These original works are full of ideas and look vigorous with perfect skills, living pictures, and local and ethnical styles. So

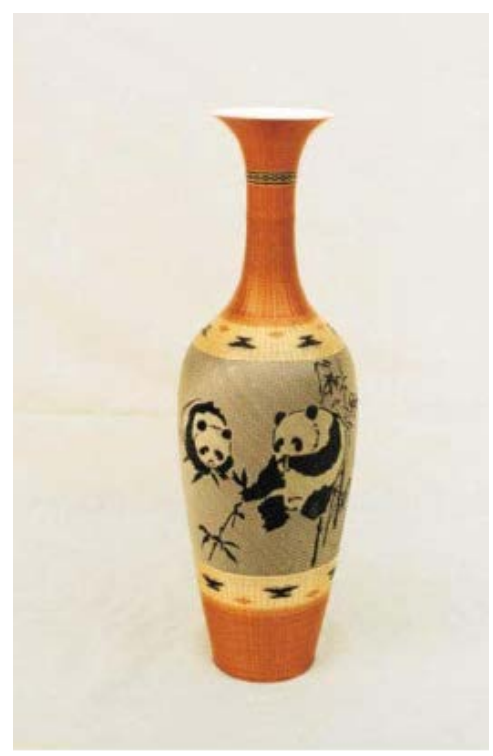

Figure 2. Bottle with Jacquard Weaving.

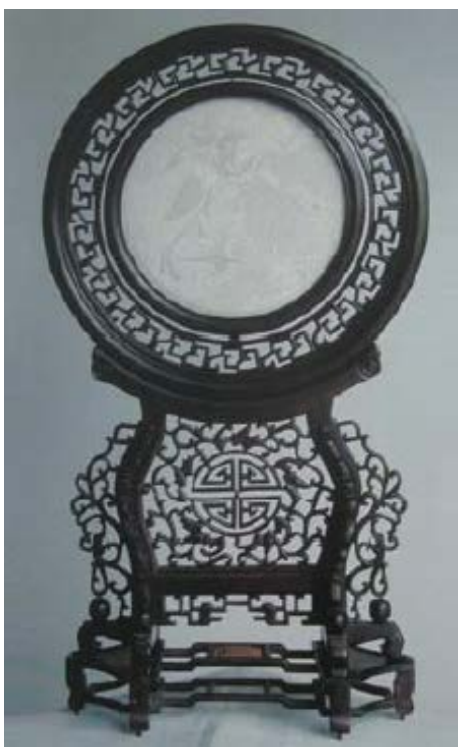

Figure 3. Double-sides Bamboo Weaving. 
"Liu's Weaving" is widely spread, which results in the advancement of the weaving skills in China.

The bamboo weavings in Quxian County has a long history, among which "Liu's Bamboo Weaving" has brought forth the new from the old by absorbing the good skills and features and grown up into one of the special treasures in China (Li, 2012). With the economical and social advancement, its existence and development is faced with some difficulties. So the paper will make clear its cultural history, find out the difficulties in the new time and discusses about its protection, inheritage and development, which is a case study of the intangible cultural inheritage in China though, yet it is significant for the development of the folk arts and crafts in $\mathrm{Ba}$ and Yu regions.

\section{Material and Procedures}

The material of "Liu's Bamboo Weaving" is mainly from a bamboo named " $S i$ nocalamus affinis", whose main feature is soft and flexible, which favorably demands the needs of the weaving.

\subsection{Materrial Features}

The main material of "Liu's Bamboo Weaving" is from a bamboo named "Sinocalamus affinis" (Term name is Neosinocalamus affinis), whose main features are its straight trunk, whose top tip is arced downward, whose height is up to 10 meters, whose $\mathrm{DBH}$ is usually $30-50 \mathrm{~cm}$, whose joint appears cylinder and whose wall is thin. The quality of the bamboo is soft and flexible, which is convenient to layer in. Its fiber is long and soft, which is fit to layering and weaving (Liu, 2012). This bamboo mainly grows in the southern provinces of China, such as Shaanxi, Hubei, Hunan, Guangxi, Sichuan, Guizhou, Yunnan, etc.

\subsection{Procedures and Skills}

"Liu's Bamboo Weaving" requires careful and close procedures, the perfect skills of which can not be replaced by modern machines. A finished production usually needs over 30 procedures from the start of cutting bamboo to the end, on which is at least spend over 15 days or even the complex procedures will be spend several months on. Its art works has two types: Porcelain Weaving and Weaving with Calligraphy and painting. Basically the procedures are similar: choice of material, separating, coloring, designing and weaving.

Up to nowadays, the six skills of "Liu's Bamboo Weaving" have been adopted, including white and black spotting, crossing, changing of strip layers, parallel intersecting, natural intersecting and zigzag intersecting. The techniques of the cubic productions include the beginning of empty round and square, and the ending has various weaving. In the weaving, the best feature is the adaptation of "Jaquard", which leads to the combination of the cubic production with parallel figurations and the association of activity and inertia. The productions look smart and spiritual. The unique "Jaquard Weaving" lies in the changing and intersecting of longitude and latitude strips and then the figuration is gradually 
presenting. The "Jaquard Art" is a weaving procedure according to an existed "Flower Sample" with an open of bent bamboo filements. The "Flower Sample" is a set of procedure in jaquard machine with weaving sample, which defines the way of warps (named foot line) and wefts (named ear line). When weaving, the foot line is connected with the ear line. When the foot line is pulled, the ear line is lifted. The design is appearing with the connection of the lines.

\section{Problems and Reasons}

By the efforts of Family Liu and through continuous innovations, "Liu's Bambboo Weaving" has a great achievement and is popular, but the identification of aestheticization and the limitedness of traditional production model result in its many problems.

\subsection{The Main Problems}

There exist many problems for the present weaving because of its own features, history or governments' supports or the others.

\subsubsection{Simple Types}

Among the handcrafts of "Liu's Bamboo Weaving, most of them are the utensils for the daily lives and its skills are traditional. The weaving products are comparatively complicated art works, so if a big product needs to be weaved, more time must be paid on. The longer period of weaving has a negative influence on its development and even on its creation and innovative production with the change of time. If the weaving abides to the tradition and has no advancement with the change of the time, it is hard to develop new products and innovative skills, which in some degree limits the development of the industry (Jiang, 2015). At nowadays, the society is changing, accordingly, the culture has been deeper understood and the aestheticization of art has been improved to a higher level. The weaving can be kept a long life only if the traditional skills have been properly inherited, developed and innovated and especially the products with the design ideas and aesthetic standards of the present tide are created to meet the demands of the time and society.

\subsubsection{Insufficient Supports from Government}

The bamboo weaving has become an art, which is utilitarian and popular and looks beautiful, but the supports from the related government are insufficient and the true attention is less paid to the traditional art works. Badly, the related departments in many districts have overlooked the "Protection Regulations of Traditional Art Works" because they have no real understanding about its significance and lack in enough attention. So the local industry of the traditional handcrafts has been looked down upon.

\subsection{About Reasons}

Any problems have their own reasons, so does the "Liu's Bamboo Weaving". As 
an art, the idea with the change of a tide plays an initial role and the identification of aestheticization has a decisive function. Besides, as an industry, its production model has a great influence on its expansion.

\subsubsection{Unchanging Style}

At present, most bamboo weaving products in Chinese market are in the similar style. These products with monotonous style and without changing have no attraction and result in the tiredness of vision. The unreformed weaving in long time can not meet the demands of society and consumers and will be labeled as the "outdated" or "low-end". The market will be widely opened with a better and faster development of weaving production and it can not be sifted out but have an advantageous position only with the ideas of keeping up with times and bringing forth the new from the old.

\subsubsection{Development Limited by Traditional Modes}

The culture of bamboo weaving art originated long time ago, but up to now, a lot of shortcomings have appeared, among which the big one is the operating idea from the producers, most of whom have no advanced production ideas and lack in the modern management experiences, who pay attention only to the production, not to the situation of market, and some of whom are keeping the traditional and single production mode and depend on laborers to weave. Their skills can not keep up with the time and have no innovations. At present, some enterprises by towns have some lower ideas or senses of modern management, but they do not get enough attraction from society and supporting of nation's policy and economy.

\section{Living Protection and Development}

"Liu's Bamboo Weaving" is a symbol of local ethnic culture and its protection means an inheritage of the culture and a protection of culture about bamboos. So it should get supports from nation. In protection, the following attention should be paid to, such as the improvement of techniques and design, the combination of culture and values and its branding.

\subsection{Its Values of Protection}

"Liu's Bamboo Weaving" takes the responsibility for the inheritage of local culture and its protection means a protection and an enhancement of culture about bamboo. Besides, its value is so important that it was listed in the "National Intangible Cultural Heritages".

\subsubsection{Responsibility of Local Culture Inheritage}

With a long and glorious history, the traditional handcraft of "Liu's Bamboo Weaving" embodies the local and traditional culture. Its themes, functions and aestheticization do not only express a form of traditional handcraft, but also fully reveals the excellence of Chinese culture, whose attraction is marvellously 
shown. The study about it can help to know about the situation of the local producing and living, the local culture and the art value behind it (Wang, 2008). Its skills are a treasurable reference for Chinese bamboo weaving art. We honestly hope that the responsibility is taken to inherit national culture, to protect the traditional handcraft, to break up the limitedness from history, to keep up with the time and to develop the bamboo weaving art.

\subsubsection{Protection and Enhancement of Bamboo Culture}

As a material from nature, bamboo was used in the old time and its advantages have been taken to the present. Bamboo symbolizes the green and health, and even a culture. Today is a time of lower-carbon and green life and the bamboo, as an environmental protection material, has been regarded as important and its advantages have been fully taken. Bamboo is chosen because of its faster growth, convenience and lower cost and it is suitable to be weaved because of its flexibility and mothproof.

\subsubsection{Supports from Nation}

"Liu's Bamboo Weaving" was listed in "The Second Batch of National Intangible Cultural Heritages" by the State Council in 2008 (Order Number: 350). Only it gets supports from nation's related policies can the excellence of Chinese intangible culture heritage be shown up and can the protection, inheritage and development of local or even national intangible culture heritages be pushed ahead. The supports from national policy and finance can improve the branding development, strengthen its cultural publicity and glorification and then it becomes a living resource.

\subsection{Measures of Development}

If "Liu's Bamboo Weaving" should be developed, the suitable and effective measures must be taken, such the improvement of techniques and design, the combination of culture and handcraft's values and the way to branding.

\subsubsection{Improvement of Techniques and Design}

The fresh life of the traditional handcraft lies in the integration of modern techniques and the production by machines must be introduced into the traditional weaving. The combination can help to improve the efficiency of production and to make a higher level of development. Besides, the weaving should absorb in excellent skills and the advanced technology can make the weaving develop faster and better. Of course, its fast saling and the fulfillment of its extra values require it express and reflect the current life.

\subsubsection{Combination of Culture and Values}

The folk art is a carrier which embodies concepts of folk culture and a result of long history. So a specific handcraft should be intergrated into more traditional cultural elements, which is not only a practical utensil, but also an art work with a higher artistic value. To develop the folk handcrafts, the production way and 
the idea of its design should be continuously innovated, such as its trade mark with an according cultural content, an utensil with relevant scripts of interpretation, a handcraft with more business values, and a work which common people can be used.

\subsubsection{The Way to Branding}

First, a specific brand should be created and a mark should be designed to match with the idea of a work. Second, the publicity should be strengthened; especially the history and culture about Quxian County should be continuously publicized so that anyone who have a look at the weaving work can know of something about its history and culture content. The advantage of Internet can be suitably taken to popularize the bamboo weaving. Besides, the sense of law and protection should be improved, which requires the related technician and manager improve their qualities so that they can provide a better protection, development and inheritage. Last, the methods of publicity can be increased, for example, its museum opens free, which helps everyone know the culture of "Liu's Bamboo Weaving" and helps them get more cognitions about the bamboo weaving art by short distant contact and the art can be protected better.

\section{Conclusion}

As one of the "National Intangible Cultural Heritages", "Liu's Bamboo Weaving" in Quxian County, Sichuan Province, embodies special skills and local culture. After a long inheritage, development and innovation, it has become an art school with special cultures and features. As one of the folk handcrafts, it is important to protect, develop and research it. The paper discusses about the full heritage and development of "Liu's Bamboo Weaving" in order to make suggestions of the art works' heritage and protection in China.

\section{Conflicts of Interest}

The authors declare no conflicts of interest regarding the publication of this paper.

\section{References}

Ji, R. X. (2016). Contemporary Inheritance and Innovation of Bamboo Weaving Crafts of Quxian. National Art Circles, No. 1, 71-75.

Jiang, J. (2015). Analyze the Development and Inheritance of Traditional National Handicrafts' Cultural Industries in Shui-Jiang-Illustrated by the Example of the Bamboo Weaving Crafts. Brand, No. 7, 253-254.

Li, Y. (2012). Practice and Research of Modern Commodity Design Based on the Traditional Bamboo Weaving Crafts. Hangzhou: China Academy of Art.

Liu, H. (2012). Heritage Protection and Daily Use-Research on the Bamboo Weaving's Transition of Qingshen in Sichuan Province. Chongqing: Sichuan Fine Arts Institute.

Wang, Y. (2008). The Traditional Handicrafts Industry in Chengdu District-Current Situation Research and Exploitation on Bamboo over Porcelain. Chengdu, Southwest Jiaotong University. 